\title{
Clinical characteristics and outcomes of mechanically ventilated elderly patients in intensive care units: a Chinese multicentre retrospective study
}

\author{
Jia-Gui Ma ${ }^{1,2}$, Bo Zhu ${ }^{1}$, Li Jiang ${ }^{1}$, Qi Jiang ${ }^{1}$, Xiu-Ming Xi ${ }^{1}$ \\ ${ }^{1}$ Department of Critical Care Medicine, Fu Xing Hospital, Capital Medical University, Beijing, China; ${ }^{2}$ Department of Critical Care Medicine, \\ Beijing Rehabilitation Hospital, Capital Medical University, Beijing, China \\ Contributions: (I) Conception and design: JG Ma, XM Xi; (II) Administrative support: XM Xi; (III) Provision of study materials: JG Ma, XM Xi; (IV) \\ Collection and assembly of data: B Zhu, L Jiang, Q Jiang; (V) Data analysis and interpretation: JG Ma, XM Xi; (VI) Manuscript writing: All authors; \\ (VII) Final approval of manuscript: All authors. \\ Correspondence to: Xiu-Ming Xi, MD. Department of Critical Care Medicine, Fu Xing Hospital, Capital Medical University, No. 20 Fuxingmenwai \\ Street, Xicheng District, Beijing 100038, China. Email: xxm2937@163.com.
}

Background: In recent years, the number of elderly patients receiving mechanical ventilation (MV) in intensive care units (ICUs) has increased. However, the evidence on the outcomes of elderly mechanically ventilated patients is scant in China. Our objective was to evaluate the characteristics and outcomes in elderly patients ( $\geq 65$ years) receiving $M V$ in the ICU.

Methods: We performed a multicentre retrospective study involving adult patients who were admitted to the ICU and received at least 24 hours of MV. Patients were divided into three age groups: under 65, 65-79, and $\geq 80$ years. The primary outcome was hospital mortality. We performed univariate and multivariate logistic regression analysis to identify factors associated with hospital mortality.

Results: A total of 853 patients were analysed. Of those, $61.5 \%$ were $\geq 65$ years of age, and $26.0 \%$ were $\geq 80$ years of age. There were significant differences in the principal reason for $M V$ among the three age groups $(\mathrm{P}<0.001)$. Advanced age was significantly associated with total duration of $M V$, ICU length of stay (LOS), and ICU costs (all $\mathrm{P}<0.001)$, but not with hospital LOS and hospital costs $(\mathrm{P}>0.05)$. In addition, mortality rates in the ICU, hospital, and at 60 days significantly increased with age (all $\mathrm{P}<0.001)$. In the age group of 80 years and older, the mortality rates were $47.7 \%$, 49.5\%, and 50.0\%, respectively. Multivariate logistic regression analysis had found that age, Acute Physiology and Chronic Health Evaluation (APACHE) II score, partial pressure of oxygen in arterial blood/fraction of inspired oxygen $\left(\mathrm{PaO}_{2} / \mathrm{FiO}_{2}\right)$ ratio, total duration of MV, ICU LOS, and the decision to withhold/withdraw life-sustaining treatments were independent influence factors for mortality rates.

Conclusions: Mechanically ventilated elderly patients ( $\geq 65$ years) have a higher ICU and hospital mortality, but the hospital LOS and hospital costs are similar to younger patients. Advanced age should be considered as a significant independent risk factor for hospital mortality of mechanically ventilated ICU patients.

Keywords: Elderly; mechanical ventilation (MV); intensive care unit; outcomes; mortality

Submitted Aug 26, 2020. Accepted for publication Feb 09, 2021.

doi: $10.21037 /$ jtd-20-2748

View this article at: http://dx.doi.org/10.21037/jtd-20-2748 


\section{Introduction}

It is well-known that population aging is already taking place in most countries and regions of the world. The proportion of the world's population aged 60 years or older increased from $8 \%$ in 1950 to $12 \%$ in 2013 . The older population is also aging itself; the proportion of persons aged 80 years or older within the older population increased from $7 \%$ in 1950 to $14 \%$ in 2013 . Twenty-three million persons aged 80 years or over were living in China in 2013 (1).

As the population ages and life expectancy increases, the number of elderly patients admitted to intensive care units (ICUs) is rapidly increasing in many countries (2-5) and has been estimated to rise considerably $(3,4)$. Elderly patients currently account for $42-52 \%$ of ICU admissions and for almost $60 \%$ of all ICU days (3,6-8). A retrospective analysis in Australia and New Zealand found an annual increase of $5.6 \%$ in the number of very elderly (age $\geq 80$ years) patients (3). The main reasons for ICU admission in elderly patients (age $\geq 65$ years) are cardiovascular issues $(23-24 \%)(7,9)$, respiratory issues (26-52\%) (10-16), trauma (29\%) (17), or sepsis $(22-32 \%)(3,18-21)$. Invasive mechanical ventilation (MV) has become one of the most common treatments used in elderly patients admitted to the ICU. About half or more of elderly patients in the ICU need MV (3,7,9-11,1416,18,21-23). With our aging population, the number of patients with $\mathrm{MV}$ will steadily increase, with a projected $80 \%$ increase by 2026 when compared to 2000 (24).

Although many clinical studies have described the clinical characteristics and outcomes of elderly patients in the ICU, there is still a lack of information on the prognosis of mechanically ventilated elderly patients in the ICU. This information is important in clinical practice when deciding whether to transfer the patient to an ICU, and whether to initiate or withdraw MV. The aim of this study is to describe clinical characteristics and outcomes of mechanically ventilated elderly patients in the ICU.

We present the following article in accordance with the STROBE reporting checklist (available at http://dx.doi. org/10.21037/ jtd-20-2748).

\section{Methods}

\section{Study setting and design}

This retrospective observational cohort study was carried out in fourteen ICUs of thirteen tertiary teaching hospitals in Beijing between January 2012 and June 2013.
Among the fourteen participating ICUs, ten were medical-surgical ICUs, two were surgical ICUs, one was a respiratory ICU, and one was a medical ICU. The number of ICU beds ranged from 8 to 20 during the study period. The study was conducted in accordance with the Declaration of Helsinki (as revised in 2013). This retrospective study was approved by the Research Ethics Boards of all participating institutions (approval number: 2019FXHEC-KY167), with a waiver of informed consent.

\section{Study population}

Patients who were admitted to the ICU and received at least 24 hours of invasive MV within the first 48 hours of ICU stay were eligible. Patients were excluded if they were less than 18 years old, had incomplete data sets, were diagnosed with neuromuscular disease, required chronic MV prior to hospital admission, or were transferred from other facilities and had already been intubated or tracheotomised. A patient was considered as one case if they were admitted to the ICU several times during the study period, and only data from the first ICU admission was analysed.

In our study, patients aged 65 years and older at the time of hospital admission, were defined as the elderly, and the cohort was divided into three age groups for analysis: under $65,65-79$, and 80 years and older. Those under 65 years of age were used as a reference population.

\section{Data collection}

For every enrolled patient, the following data were recorded: demographic and epidemiological characteristics; reason for ICU admission; comorbidities; severity of illness; primary reason for MV; MV parameters and settings; sedatives, analgesics, and neuromuscular blockers used during MV; total duration of MV; ventilator-free days (25); the occurrence of successful weaning within 28 days; ICU and hospital length of stay (LOS); ICU and hospital costs; complications of $\mathrm{MV}$; the occurrence of withholding or withdrawing life-sustaining treatments; and discharge destination. To obtain survival data after hospital discharge, we contacted survivors, their relatives, or their general practitioner or nursing homes by phone.

Severity of illness was assessed using the Acute Physiology and Chronic Health Evaluation (APACHE) II score (26). The severity of illness as rated by the APACHE II score was given with and without age points to illustrate the impact that age has on the score. 


\section{Outcomes of interest}

The primary outcome was hospital mortality. Secondary outcomes included the total duration of MV, ICU and hospital LOS, and ICU and 60-day mortality rates.

\section{Statistical analysis}

Statistical analyses were carried out using SPSS 21.0 (SPSS Inc., Chicago, Illinois, USA). Data were expressed as the mean \pm standard deviation (SD) for normally distributed continuous variables, the median [interquartile range (IQR)] for non-normally distributed variables, and the number (percentage) for categorical variables. Continuous variables were compared using the Kruskal-Wallis test or the MannWhitney $\mathrm{U}$ test. Categorical variables were compared using the chi-square or Fisher's exact tests. Logistic regression analysis was used to determine risk factors for the ICU, hospital, and 60-day mortality rates. Variables were introduced into the model based on clinical and statistical significance ( $\mathrm{P}$ value $<0.2$ on univariate analysis). We then performed three separate multivariate logistic regression analyses using a forward selection procedure to determine risk factors for ICU mortality (first analysis), hospital mortality (second analysis), and 60-day mortality (third analysis). We defined cut-off points for ICU LOS and total duration of $M V$ to create a binary dependent variable: seven days for ICU stay and five days for total duration of MV. These cut-off points were chosen because they were the median values for the variables. A two-sided $\mathrm{P}$ value $<0.05$ was considered statistically significant.

\section{Results}

\section{Baseline characteristics}

A total of 853 patients were included in this study. Of these, there were 328 patients under the age of 65 years (38.5\%), 303 patients aged $65-79$ years (35.5\%), and 222 patients aged 80 years and older $(26.0 \%)$. Table 1 presents baseline demographics and clinical characteristics of mechanically ventilated patients in the ICU. There were statistically significant differences in body mass index (BMI) and smoking history among the three age groups. However, significant differences were not found among the three age groups due to gender, past history of surgery, and non-invasive mechanical ventilation (NIMV) before ICU admission.

With advancing age, patients admitted to the ICU were more likely to be from the medical ward (from $13.1 \%$ in the age group under 65 years to $32.4 \%$ in the age group of 80 years and older), while the proportion from the surgical ward decreased $(54.0 \%$ in the age group under 65 years to $30.6 \%$ in the age group of 80 years and older).

With increasing age, the prevalence of some pre-existing comorbidities such as hypertension, chronic renal failure, chronic heart failure, chronic obstructive pulmonary disease (COPD), cancer, and stroke significantly increased. The prevalence of having two or more comorbidities also increased with age $(\mathrm{P}<0.001)$. In the two older age groups, more than $50 \%$ of patients had two or more comorbidities.

\section{ICU hospitalization characteristics}

Table 2 presents the hospitalization characteristics of mechanically ventilated patients in the ICU. The APACHE II scoring system was used to assess the severity of illness in patients admitted to the ICU, both with and without age points. There was a significant difference among the three age groups with median APACHE scores of 13 points (IQR, 8-19) in the age group under 65 years, 18 points (IQR, 12-24) in the age group of 65-79 years, and 19 points (IQR, 13-24) in the age group 80 years and older $(\mathrm{P}<0.001)$. When compared with patients aged less than 65 years, the two older age groups had higher APACHE scores (both $\mathrm{P}<0.001)$. After filtering out the age points, there was still a significant difference in APACHE scores between the age group under 65 years and the age group of 80 years and older [11 points (IQR, 6-17) vs. 14 points (IQR, 8-19), $\mathrm{P}=0.034]$; however, there was not a significant difference between the age group under 65 years and the age group of $65-79$ years $(\mathrm{P}=0.114)$.

We found significant differences among the three age groups $(\mathrm{P}<0.001)$ in the principal reason for $\mathrm{MV}$ : pneumonia $(31.1 \%)$ was the most prevalent reason for the initiation of $\mathrm{MV}$ in the age group of 80 years and older, followed by postoperative status $(23.4 \%)$, as well as COPD or asthma (10.4\%) and congestive heart failure (10.4\%). However, the most prevalent reason for $\mathrm{MV}$ in the age group under 65 years old and the age group between 65 and 79 years old was postoperative status ( $48.2 \%$ and $37.0 \%$, respectively), followed by pneumonia ( $11.9 \%$ and $17.2 \%$, respectively) and acute respiratory distress syndrome (ARDS; $9.8 \%$ and $10.9 \%$, respectively).

Arterial blood gas analysis before $\mathrm{MV}$ in the three age groups showed statistical differences in partial pressure of oxygen in arterial blood/fraction of inspired oxygen $\left(\mathrm{PaO}_{2} / \mathrm{FiO}_{2}\right)$ 
Table 1 Baseline characteristics of mechanically ventilated patients in ICU

\begin{tabular}{|c|c|c|c|c|}
\hline Variable & $<65$ years $(n=328)$ & $65-79$ years $(n=303)$ & $\geq 80$ years $(n=222)$ & $P$ value \\
\hline Female, n (\%) & $120(36.6)$ & $117(38.6)$ & $77(34.7)$ & 0.650 \\
\hline BMI $\left(\mathrm{kg} / \mathrm{m}^{2}\right)$ & $24(21,26)$ & $23(21,25)$ & $22(19,24)^{\star \#}$ & $<0.001$ \\
\hline History of smoking, n (\%) & $118(36.0)$ & $123(40.6)$ & $60(27.0)^{\#}$ & 0.005 \\
\hline NIMV before ICU admission & $41(12.5)$ & $42(13.9)$ & $19(8.6)$ & 0.168 \\
\hline ICU admission source, n (\%) & & & & $<0.001$ \\
\hline Medical ward & $43(13.1)$ & $70(23.1)^{\star}$ & $72(32.4)^{*}$ & $<0.001$ \\
\hline Surgical ward & $177(54.0)$ & $152(50.2)$ & $68(30.6)^{\star \#}$ & $<0.001$ \\
\hline \multicolumn{5}{|l|}{ Comorbidities, n (\%) } \\
\hline Hypertension & $77(23.5)$ & $183(60.4)^{\star}$ & $143(64.4)^{\star}$ & $<0.001$ \\
\hline Diabetes & $42(12.8)$ & $113(37.3)^{\star}$ & $78(35.1)^{\star}$ & $<0.001$ \\
\hline Chronic renal failure & $25(7.6)$ & $36(11.9)$ & $36(16.2)^{*}$ & 0.007 \\
\hline Chronic heart failure & $9(2.7)$ & $34(11.2)^{*}$ & $37(16.7)^{\star}$ & $<0.001$ \\
\hline COPD & $8(2.4)$ & $38(12.5)^{\star}$ & $39(17.6)^{*}$ & $<0.001$ \\
\hline Cirrhosis & $7(2.1)$ & $2(0.7)$ & $2(0.9)$ & 0.249 \\
\hline Pulmonary fibrosis & $10(3.0)$ & $9(3.0)$ & $6(2.7)$ & 0.971 \\
\hline$\geq 2$ & $61(18.6)$ & $158(52.1)$ & $134(60.4)$ & \\
\hline
\end{tabular}

${ }^{a}$, comorbidities included hypertension, insulin-dependent diabetes, chronic renal failure, chronic heart failure [New York Heart Association (NYHA) functional classification III-IV], chronic obstructive pulmonary disease, cirrhosis, pulmonary fibrosis, cancer, and brain stroke; b, comparison among the three age groups; *, $\mathrm{P}<0.05$, significantly different from the group of patients aged under 65 years; *, $\mathrm{P}<0.05$, significantly different from the group of 65-79 years. ICU, intensive care unit; MD, median; IQR, interquartile range; BMI, body mass index; MV, mechanical ventilation; NIMV, non-invasive mechanical ventilation; APACHE II, Acute Physiology and Chronic Health Evaluation II; COPD, chronic obstructive pulmonary disease.

ratio $(\mathrm{P}=0.026)$, partial pressure of carbon dioxide $\left(\mathrm{PaCO}_{2}\right.$, $\mathrm{P}<0.001)$, and pulse oxygen saturation $\left(\mathrm{SpO}_{2}, \mathrm{P}<0.001\right)$, but this was not observed in arterial $\mathrm{pH}(\mathrm{P}=0.126)$.

The combination of synchronized intermittent mandatory ventilation and pressure support mode (SIMV + PSV) was the most preferred mode of MV in the three age groups $(39.0 \%, 43.6 \%$, and $34.2 \%$ in the under 65 years age group, 65-79 years old group, and 80 years and older group, respectively). However, the MV mode was not significantly different among the three age groups $(\mathrm{P}=0.404)$.

Regarding the management of patients during $\mathrm{MV}$, significant differences were found in tidal volume (VT; $\mathrm{P}<0.001)$ and the use of analgesics $(\mathrm{P}<0.001)$ among the three age groups. In the whole cohort, more than $70 \%$ 
Table 2 Hospitalization characteristics of mechanically ventilated patients in ICU

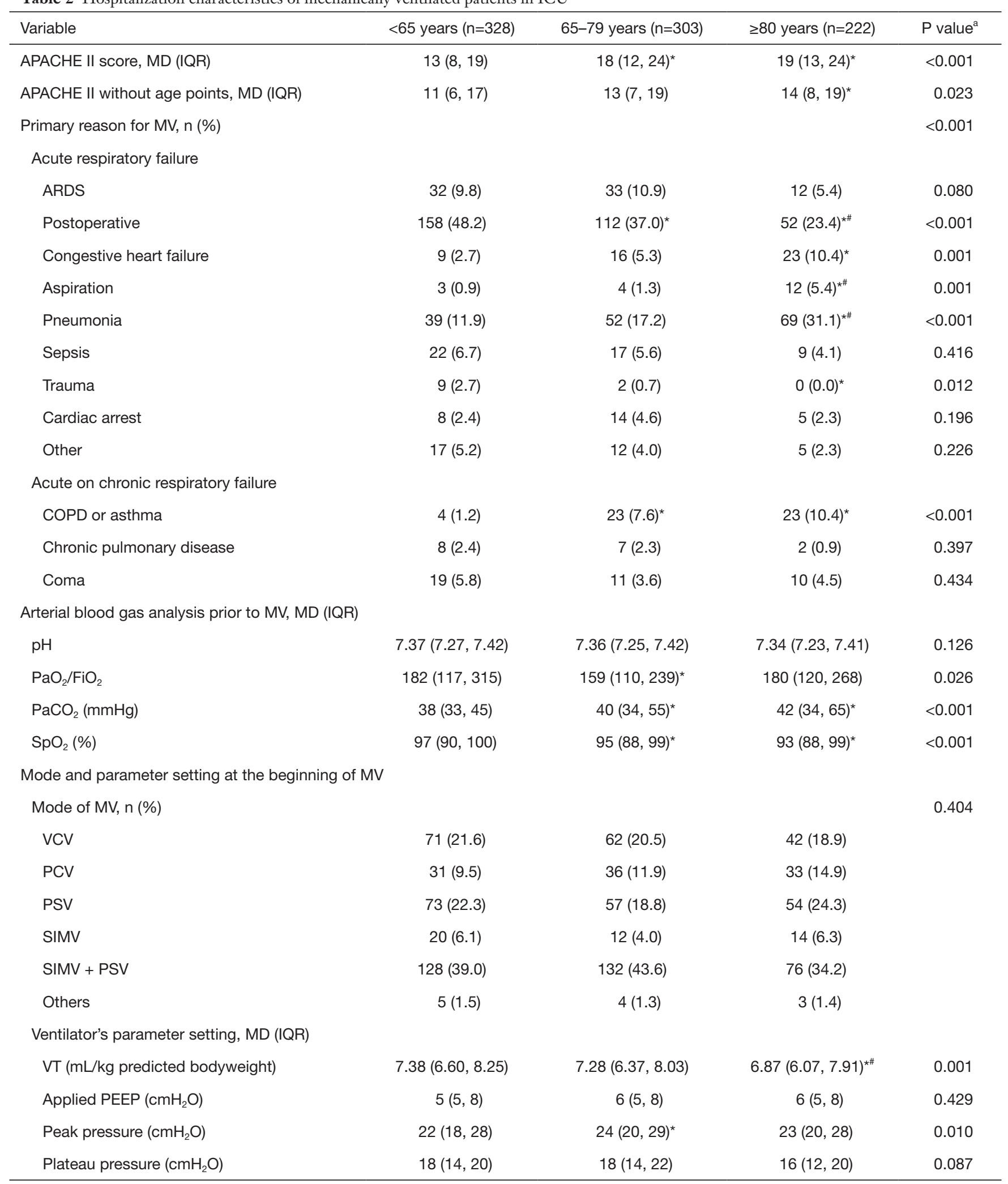

Table 2 (continued) 
Table 2 (continued)

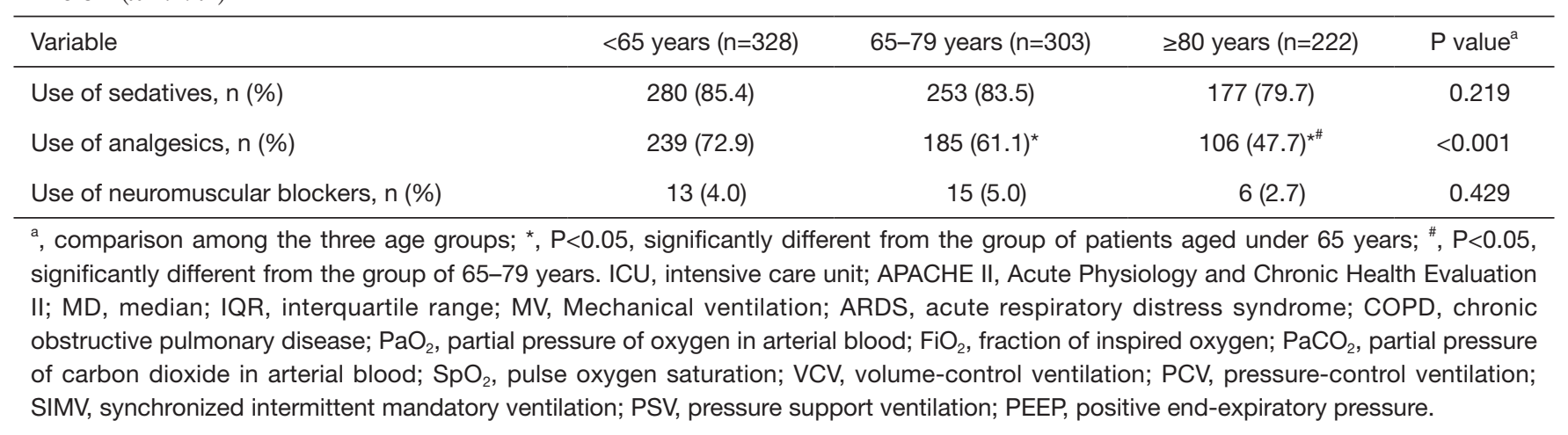

(71.9\%) of patients were ventilated with a VT $<8 \mathrm{~mL} / \mathrm{kg}$ of predicted bodyweight, and in the third age group, the proportion of patients with a $\mathrm{VT}<8 \mathrm{~mL} / \mathrm{kg}$ of predicted bodyweight was the highest $(76.1 \%)$. The proportion of patients using analgesics in the three age groups decreased with age $(72.9 \%$ in the age group under 65 years to $47.7 \%$ in the age group of 80 years and older). There were no significant differences in the median levels of positive end expiratory pressure (PEEP) and platform pressure among the three age groups, or in the use of sedatives and neuromuscular blockers (all $\mathrm{P}>0.05$ ).

\section{Clinical courses and outcomes}

Table 3 presents the clinical courses and outcomes in each of the three age groups. There were statistically significant differences in the total duration of $M V(P<0.001)$, ventilator-free days $(\mathrm{P}<0.001)$, and successful weaning rate within 28 days $(\mathrm{P}<0.001)$ among the three age groups. As shown in Table 3, it can be clearly seen that compared with patients in the group aged 65-79 years and the group aged under 65 years, the total MV time of patients in the age group of 80 years and older increased significantly, while the ventilator-free days, and successful weaning rate within 28 days decreased significantly. Only the total duration of MV between the two older age groups had no statistically significant difference [135 (IQR, 59-280) vs. 165 (IQR, 67-404) hours, $\mathrm{P}=0.101]$.

There was no statistically significant difference in the hospital LOS among the three age groups $(\mathrm{P}=0.749)$. However, the difference in the ICU LOS did differ significantly $(\mathrm{P}<0.001)$. In the group of patients aged 80 and older, the ICU LOS was 13 days (IQR, 6-24 days), as compared with 8 days (IQR, 4-19 days) for patients aged
65-79 years $(\mathrm{P}=0.005)$ and 7 days (IQR, 4-14 days) for patients aged under 65 years $(\mathrm{P}<0.001)$.

Mortality rates in the ICU, hospital, and at 60 days significantly increased with age. In the age group of 80 years and older, the hospital mortality rate was $49.5 \%$, which was significantly different from the $19.8 \%$ rate for the age group under 65 years $(\mathrm{P}<0.001)$ and the $35.0 \%$ rate for the age group of $65-79$ years $(\mathrm{P}=0.001)$. There was also a significant difference in the hospital mortality rate between the age group 65-79 years and the age group under 65 years $(\mathrm{P}<0.001)$. The same was true for ICU mortality and 60 -day mortality rates.

There was no statistically significant difference in hospital costs among the three age groups $(\mathrm{P}=0.084)$. However, ICU costs did differ significantly $(\mathrm{P}<0.001)$. The ICU costs were higher in the age group of $65-79$ years (with a median of $68,000 \mathrm{CNY}$ ) and the age group of 80 years and older (with a median of $89,000 \mathrm{CNY}$ ) than those in the age group under 65 years (with a median of $57,000 \mathrm{CNY} ; \mathrm{P}=0.030$ and $\mathrm{P}<0.001$, respectively), but there was no significant difference between the two elderly groups $(\mathrm{P}=0.061)$.

Table 3 also shows the rate of events that occurred over the course of MV. The proportion of patients who required reintubation tended to be higher in the age group of 80 years and older. Furthermore, the rates of subsequent ventilator-associated pneumonia and the proportion of patients who underwent prolonged MV were significantly higher in the age group of 80 years and older (all $\mathrm{P}<0.01$ ). In addition, the decision to withhold or withdraw lifesustaining treatments tended to be much more often in the age group of 80 years and older (19.4\%). A considerable proportion of the 572 patients who survived the hospital were discharged home. Additionally, the proportion of 
Table 3 Clinical course and outcomes of mechanically ventilated patients in ICU

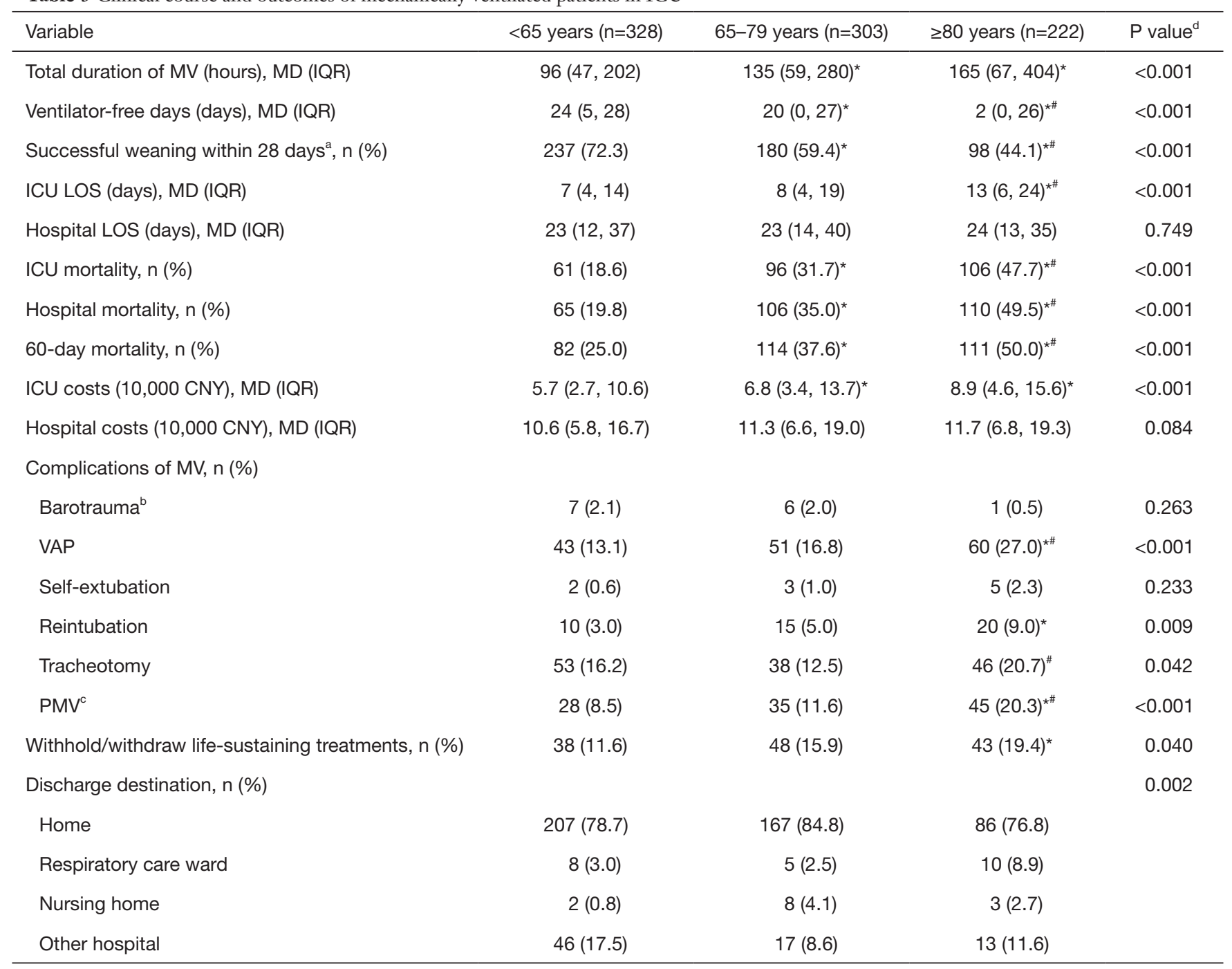

${ }^{a}$, successful weaning from MV was defined as complete respiratory autonomy for at least $48 \mathrm{~h}$; ${ }^{\mathrm{b}}$, Barotrauma refers to the development of at least one of the following: interstitial emphysema, pneumothorax, pneumomediastinum, pneumoperitoneum or subcutaneous emphysema; ${ }^{\circ}$, PMV was defined as the need for mechanical ventilation for more than 21 days; ${ }^{d}$, comparison among the three age groups; *, $\mathrm{P}<0.05$, significantly different from the group of patients aged under 65 years; *, $\mathrm{P}<0.05$, significantly different from the group of $65-79$ years. ICU, intensive care unit; MV, Mechanical ventilation; MD, median; IQR, interquartile range; LOS, length of stay; CNY, Chinese yuan; VAP, ventilator-associated pneumonia; PMV, prolonged mechanical ventilation.

patients that survived discharge and returned home in all three age groups was similar. However, in the age group of 80 years and older, nearly one-ninth $(8.9 \%)$ of survivors were transferred to a respiratory care ward.

\section{Univariate and multivariate logistic regression analyses}

Table 4 presents the statistical results of univariate and multivariate analyses for ICU mortality, hospital mortality, and 60-day mortality. Multivariate logistic regression analysis had found that age, APACHE II score, $\mathrm{PaO}_{2} / \mathrm{FiO}_{2}$ ratio, total duration of $\mathrm{MV}$, ICU LOS, and the decision to withhold/withdraw life-sustaining treatments were independent influence factors for ICU mortality, hospital mortality, and 60-day mortality. In addition, the number of comorbidities was also an independent risk factor for ICU mortality. Multivariate logistic regression analysis also showed that when compared with the reference group 
Table 4 Results of the logistic regression analyses

\begin{tabular}{|c|c|c|c|c|c|c|}
\hline \multirow{2}{*}{ Variable } & \multicolumn{2}{|l|}{ ICU mortality } & \multicolumn{2}{|l|}{ Hospital mortality } & \multicolumn{2}{|c|}{ 60-day mortality } \\
\hline & OR $(95 \% \mathrm{Cl})$ & $P$ value & OR $(95 \% \mathrm{Cl})$ & $P$ value & OR $(95 \% \mathrm{Cl})$ & $P$ value \\
\hline \multicolumn{7}{|l|}{ Univariate analysis } \\
\hline \multicolumn{7}{|l|}{ Age groups (vs. <65) } \\
\hline $65-79$ & $2.030(1.404-2.935)$ & $<0.001$ & $2.177(1.519-3.120)$ & $<0.001$ & $1.810(1.286-2.546)$ & 0.001 \\
\hline$\geq 80$ & $4.000(2.727-5.867)$ & $<0.001$ & $3.974(2.723-5.800)$ & $<0.001$ & $3.000(2.087-4.312)$ & $<0.001$ \\
\hline BMI $\left(\mathrm{kg} / \mathrm{m}^{2}\right)$ & $0.922(0.886-0.958)$ & $<0.001$ & $0.925(0.891-0.961)$ & $<0.001$ & $0.933(0.899-0.968)$ & $<0.001$ \\
\hline History of smoking & $1.160(0.857-1.568)$ & 0.337 & $1.144(0.850-1.540)$ & 0.373 & $1.159(0.866-1.551)$ & 0.320 \\
\hline ICU admission source: Medical ward & $3.373(1.209-9.427)$ & 0.020 & $2.581(1.848-3.604)$ & $<0.001$ & $2.857(2.047-3.988)$ & $<0.001$ \\
\hline \multicolumn{7}{|l|}{ No. of comorbidities (vs. none) } \\
\hline 1 & $2.145(1.408-3.269)$ & $<0.001$ & $1.941(1.296-2.907)$ & 0.001 & $1.784(1.209-2.631)$ & 0.004 \\
\hline$\geq 2$ & $3.280(2.238-4.807)$ & $<0.001$ & $2.854(1.979-4.115)$ & $<0.001$ & $2.658(1.869-3.780)$ & $<0.001$ \\
\hline APACHE II score & $1.106(1.084-1.129)$ & $<0.001$ & $1.101(1.079-1.123)$ & $<0.001$ & $1.098(1.076-1.119)$ & $<0.001$ \\
\hline Cause of MV: pneumonia & $2.082(1.462-2.964)$ & $<0.001$ & $2.154(1.517-3.058)$ & $<0.001$ & $2.329(1.643-3.302)$ & $<0.001$ \\
\hline $\mathrm{PaCO}_{2}(\mathrm{mmHg})$ & $1.005(0.998-1.012)$ & 0.143 & $1.005(0.998-1.011)$ & 0.173 & $1.004(0.997-1.010)$ & 0.278 \\
\hline $\mathrm{PaO}_{2} / \mathrm{FiO}_{2}$ & $0.998(0.997-0.999)$ & 0.001 & $0.998(0.997-0.999)$ & 0.002 & $0.998(0.997-0.999)$ & 0.001 \\
\hline Total duration of $\mathrm{MV} \geq 5$ days & $3.378(2.473-4.615)$ & $<0.001$ & $2.984(2.208-4.033)$ & $<0.001$ & $2.953(2.203-3.960)$ & $<0.001$ \\
\hline ICU LOS $\geq 7$ days & $1.287(0.951-1.742)$ & 0.102 & $1.334(0.991-1.797)$ & 0.058 & $1.379(1.030-1.845)$ & 0.031 \\
\hline $\begin{array}{l}\text { Withhold/withdraw life-sustaining } \\
\text { treatments }\end{array}$ & $10.775(6.941-16.727)$ & $<0.001$ & 11.567 (7.326-18.262) & $<0.001$ & $19.394(11.202-33.577)$ & $<0.001$ \\
\hline \multicolumn{7}{|l|}{ Multivariate analysis } \\
\hline \multicolumn{7}{|l|}{ Age groups (vs. <65) } \\
\hline $65-79$ & $1.348(0.838-2.171)$ & 0.218 & $1.442(0.908-2.290)$ & 0.121 & $1.312(0.832-2.068)$ & 0.242 \\
\hline$\geq 80$ & $2.799(1.714-4.573)$ & $<0.001$ & $2.519(1.558-4.072)$ & $<0.001$ & $1.843(1.141-2.977)$ & 0.012 \\
\hline $\mathrm{BMI}\left(\mathrm{kg} / \mathrm{m}^{2}\right)$ & $0.957(0.910-1.005)$ & 0.081 & $0.960(0.914-1.008)$ & 0.099 & $0.964(0.918-1.011)$ & 0.134 \\
\hline ICU admission source: Medical ward & $1.211(0.774-1.895)$ & 0.401 & $1.356(0.872-2.106)$ & 0.176 & $1.540(1.001-2.370)$ & 0.050 \\
\hline \multicolumn{7}{|l|}{ No. of comorbidities (vs. none) } \\
\hline 1 & $1.441(0.822-2.527)$ & 0.202 & $1.409(0.816-2.432)$ & 0.218 & $1.260(0.739-2.148)$ & 0.395 \\
\hline$\geq 2$ & $1.835(1.065-3,162)$ & 0.029 & $1.667(0.981-2.835)$ & 0.059 & $1.438(0.854-2.421)$ & 0.172 \\
\hline APACHE II score & $1.085(1.058-1.113)$ & $<0.001$ & $1.079(1.053-1.106)$ & $<0.001$ & $1.069(1.043-1.095)$ & $<0.001$ \\
\hline Cause of MV: pneumonia & $0.958(0.596-1.540)$ & 0.859 & $1.036(0.649-1.655)$ & 0.881 & $1.245(0.781-1.985)$ & 0.357 \\
\hline $\mathrm{PaCO}_{2}(\mathrm{mmHg})$ & $0.996(0.987-1.004)$ & 0.308 & $0.995(0.987-1.003)$ & 0.245 & $0.994(0.985-1.002)$ & 0.144 \\
\hline $\mathrm{PaO}_{2} / \mathrm{FiO}_{2}$ & $0.999(0.998-1.000)$ & 0.027 & $0.999(0.998-1.000)$ & 0.046 & $0.999(0.998-1.000)$ & 0.016 \\
\hline Total duration of $M V \geq 5$ days & $5.046(2.653-9.598)$ & $<0.001$ & $3.761(2.086-6.782)$ & $<0.001$ & 3.449 (1.951-6.097) & $<0.001$ \\
\hline ICU LOS $\geq 7$ days & $0.253(0.131-0.491)$ & $<0.001$ & $0.358(0.195-0.658)$ & 0.001 & $0.369(0.205-0.666)$ & 0.001 \\
\hline $\begin{array}{l}\text { Withhold/withdraw life-sustaining } \\
\text { treatments }\end{array}$ & 7.828 (4.710-13.009) & $<0.001$ & $8.741(5.210-14.666)$ & $<0.001$ & $14.323(7.882-26.028)$ & $<0.001$ \\
\hline
\end{tabular}

OR, odds ratio; ICU, intensive care unit; BMI, body mass index; APACHE II, Acute Physiology and Chronic Health Evaluation II; MV, Mechanical ventilation; $\mathrm{PaCO}_{2}$, partial pressure of carbon dioxide in arterial blood; $\mathrm{PaO}_{2}$, partial pressure of oxygen in arterial blood; FiO ${ }_{2}$, fraction of inspired oxygen; LOS, length of stay. 
(under 65 years) and adjusted for other variables, the odds ratios of ICU death, hospitalization death and death within 60 days in patients aged 80 years and older were 2.799 (95\% CI: $1.714-4.573), 2.519$ (95\% CI: 1.558-4.072) and 1.843 (95\% CI: 1.141-2.977), respectively.

\section{Discussion}

In this multicentre retrospective study, our main findings were that the elderly account for a major proportion of adult patients receiving MV in ICU. Mechanically ventilated elderly patients have a lower ICU, hospital and 60-day survival, but the hospital LOS and hospital costs are similar to younger patients. Advanced age should be considered as an important independent risk factor for mortality rates of patients receiving $M V$ in the ICU.

In recent decades, a few studies have shown that the proportion of elderly patients receiving $\mathrm{MV}$ treatment in ICUs reaches $25.4-50.5 \%$ (27-30). In our study, we found that this proportion of elderly patients was up to $61.5 \%$, and the proportion of very elderly patients was up to $26.0 \%$, which was significantly higher than in the previous studies. There are several reasons why this might be the case, including the following: first, it is well-known that population aging is taking place much more rapidly now in developing countries than it had in developed countries in the past. In particular, China is one of the fastest aging countries in the world (1). This demographic trend is bound to increase the demand for health care resources. Secondly, there is still a lack of well-defined thresholds for elderly patients, and the definition of the term "elderly" has varied from 65 to 75 years old $(7,10,22,23,27,29-36)$. Therefore, the research results may differ.

As reported by others, acute respiratory failure was the most frequent indication for $\mathrm{MV}(27,28,30,37)$, accounting for $87.5 \%$ of the principal reason for MV for our total study group. There were statistically significant differences in the principal reason for $\mathrm{MV}$ among the three age groups $(\mathrm{P}<0.001)$. Compared with the other two age groups, very elderly (age $\geq 80$ years) patients were more likely to receive MV for medical indications (pneumonia, aspiration, and congestive heart failure) and less likely to receive $M V$ for postoperative reasons and trauma. Esteban et al. (27) also found that older patients (age $>70$ years) were ventilated because of cardiac diseases (heart failure and cardiac arrest) and fewer were ventilated because of coma, ARDS and trauma. The reasons for this may be explained as follows: first, we found that with age, patients admitted to the ICU were more likely to come from the medical ward, while the proportion coming from surgical wards declined. Secondly, in our study, we found that the prevalence of having two or more comorbidities increased with age in patients with $\mathrm{MV}$ in the ICU $(\mathrm{P}<0.001)$. Having several organ dysfunctions and failures, such as cardiovascular and respiratory dysfunction and failure increased the relative risk of receiving MV. Multivariate analysis revealed that factors such as increasing age, New York Heart Association (NYHA) functional classification III or IV, neurologic and respiratory reasons for admission, emergency surgery; pneumonia, and lower Glasgow Coma Score were associated with the use of MV (38).

Unlike other studies $(28,38)$, our study shows that SIMV + PSV was the main invasive ventilatory mode in the whole group as well as in all three age groups, followed by assist-control ventilation and PSV. In fact, this may reflect heterogeneity in the selection of ventilatory modes in different ICUs and countries $(37,38)$. However, there was no statistically significant difference in ventilatory modes among the three age groups $(\mathrm{P}=0.404)$. In our cohort, the median VT setting was $7.26 \mathrm{~mL} / \mathrm{kg}$ of predicted bodyweight (IQR, 6.37-8.11), a value lower than that described in some studies $(28,37,38)$. More than $70 \%$ (71.9\%) of patients were ventilated with a VT $<8 \mathrm{~mL} / \mathrm{kg}$ of predicted bodyweight, and this proportion increased with age. This value is greater than the $48.4 \%$ reported by Metnitz et al. in a multinational cohort (38). This may be related to the median $\mathrm{PaO}_{2} / \mathrm{FIO}_{2}$ ratios being $<200$ in the three age groups. Metnitz et al. found that patients with the lowest $\mathrm{PaO}_{2} / \mathrm{FIO}_{2}$ ratios were ventilated more often with tidal volumes $<8 \mathrm{~mL} / \mathrm{kg}$ of body weight, than patients with higher $\mathrm{PaO}_{2} / \mathrm{FiO}_{2}$ ratios (38).

Age has always been considered to be a factor in increased ICU resource utilization. Our findings may support this. In this study, we found statistically significant differences in duration of MV, length of ICU stay, and ICU costs among the three age groups. However, this does not mean that the length of hospital stays and hospital costs of elderly patients have increased significantly. The association between age and hospital costs in patients receiving $M V$ was studied by Chelluri et al. (39). They found that daily and total hospital costs were lower in older patients. They suggest that the lower resource use for older patients may be related to a preference for less aggressive care by elderly patients and their families or by healthcare providers. We also support this view because we found that the decision to withhold or withdraw life-sustaining treatments tended to be much more often with aging. Moreover, Turnbull et al. (40) 
have also shown a higher rate of limiting life support among older patients.

Our results suggest that ICU mortality, hospital mortality, and 60-day mortality of ventilated elderly patients in the ICU are significantly elevated. Age was strongly associated with mortality rates of mechanically ventilated elderly patients in the ICU, and remained a strong predictor of mortality even after adjusting for other variables. Our study adopted the most widely used criteria to define an elderly population, and analyzed the relationship between age and ICU mortality, hospital mortality and 60-day mortality in the three age intervals. We present the results of a quantitative assessment of increased risk of death associated with specific age intervals ( $\geq 80$ years).

To our knowledge, this is the first study in China to evaluate the characteristics and outcomes in elderly patients ( $\geq 65$ years) receiving $\mathrm{MV}$ in the ICU. However, we also are aware of several limitations of our study. First, this study is a retrospective study, and the data were obtained in 2012-2013, which may impose temporal limitations on the applicability of this data set. Second, we only evaluated ICU mortality, hospital mortality, and 60-day mortality, without discussing long-term mortality, activities of daily living (ADL), and quality of life (QOL) after discharge, because we did not collect relevant data. Future studies should focus on long-term mortality, physical rehabilitation, and QOL of elderly patients discharged from the hospital. Third, we did not collect data on clinical and laboratory variables during the period of $\mathrm{MV}$, such as changes in blood pressure, heart rate, respiratory rate, $\mathrm{pH}, \mathrm{PaO}_{2}, \mathrm{PaCO}_{2}, \mathrm{SpO}_{2}$, and ventilator parameters. Thus, we cannot further assess the effectiveness of MV.

\section{Conclusions}

In conclusion, the results obtained in the present study indicate that the elderly patients constitute a major proportion of adult patients receiving $\mathrm{MV}$ in the ICU.

The elderly mechanically ventilated patients ( $\geq 65$ years) have a higher ICU and hospital mortality, but the hospital LOS and hospital costs are similar to younger patients. Advanced age should be considered as a significant independent risk factor for hospital mortality of mechanically ventilated ICU patients. Evaluating the clinical characteristics and outcomes of elderly mechanically ventilated patients has become important in terms of the effective use of limited medical resources and making decisions for clinicians, patients and their families.

\section{Acknowledgments}

Funding: None.

\section{Footnote}

Reporting Checklist: The authors have completed the STROBE reporting checklist. Available at http://dx.doi. org/10.21037/jtd-20-2748

Data Sharing Statement: Available at http://dx.doi. org/10.21037/jtd-20-2748

Conflicts of Interest: All authors have completed the ICMJE uniform disclosure form (available at http://dx.doi. org/10.21037/ jtd-20-2748). The authors have no conflicts of interest to declare.

Ethical Statement: The authors are accountable for all aspects of the work in ensuring that questions related to the accuracy or integrity of any part of the work are appropriately investigated and resolved. The study was conducted in accordance with the Declaration of Helsinki (as revised in 2013). This retrospective study was approved by the Research Ethics Boards of all participating institutions (approval number: 2019FXHEC-KY167), with a waiver of informed consent.

Open Access Statement: This is an Open Access article distributed in accordance with the Creative Commons Attribution-NonCommercial-NoDerivs 4.0 International License (CC BY-NC-ND 4.0), which permits the noncommercial replication and distribution of the article with the strict proviso that no changes or edits are made and the original work is properly cited (including links to both the formal publication through the relevant DOI and the license). See: https://creativecommons.org/licenses/by-nc-nd/4.0/.

\section{References}

1. United Nations, Department of Economic and Social Affairs, Population Division (2013). World Population Ageing 2013. ST/ESA/SER.A/348 2013. Available online: http://www.un.org/en/development/desa/population/ publications/ageing/WorldPopulationAgeing2013.shtml. Accessed 02 Mar 2019.

2. Wunsch H, Linde-Zwirble WT, Harrison DA, et al. Use of intensive care services during terminal hospitalizations 
in England and the United States. Am J Respir Crit Care Med 2009;180:875-80.

3. Bagshaw SM, Webb SA, Delaney A, et al. Very old patients admitted to intensive care in Australia and New Zealand: a multi-centre cohort analysis. Crit Care 2009;13:R45.

4. Laake JH, Dybwik K, Flaatten HK, et al. Impact of the post-World War II generation on intensive care needs in Norway. Acta Anaesthesiol Scand 2010;54:479-84.

5. Nguyen YL, Angus DC, Boumendil A, et al. The challenge of admitting the very elderly to intensive care. Ann Intensive Care 2011;1:29.

6. Marik PE. Management of the critically ill geriatric patient. Crit Care Med 2006;34:S176-82.

7. Fuchs L, Chronaki CE, Park S, et al. ICU admission characteristics and mortality rates among elderly and very elderly patients. Intensive Care Med 2012;38:1654-61 .

8. Docherty A, Lone N, Anderson N, et al. Epidemiology and outcomes of older patients admitted to Scottish intensive care units: a national database linkage study. Lancet 2015;385:S33.

9. Ball IM, Bagshaw SM, Burns KE, et al. Outcomes of elderly critically ill medical and surgical patients: a multicentre cohort study. Can J Anaesth 2017;64:260-9.

10. Sacanella E, Pérez-Castejón JM, Nicolás JM, et al. Mortality in healthy elderly patients after ICU admission. Intensive Care Med 2009;35:550-5.

11. Tabah A, Philippart F, Timsit JF, et al. Quality of life in patients aged 80 or over after ICU discharge. Crit Care 2010;14:R2.

12. Heyland D, Cook D, Bagshaw SM, et al. The Very Elderly Admitted to ICU: A Quality Finish? Crit Care Med 2015;43:1352-60.

13. Tripathy S, Mishra JC, Dash SC. Critically ill elderly patients in a developing world--mortality and functional outcome at 1 year: a prospective single-center study. J Crit Care 2014;29:474.e7-13.

14. Ball IM, Bagshaw SM, Burns KE, et al. A clinical prediction tool for hospital mortality in critically ill elderly patients. J Crit Care 2016;35:206-12.

15. Le Borgne P, Maestraggi Q, Couraud S, et al. Critically ill elderly patients $(>/=90$ years): Clinical characteristics, outcome and financial implications. PLoS One 2018;13:e198360.

16. Lerolle N, Trinquart L, Bornstain C, et al. Increased intensity of treatment and decreased mortality in elderly patients in an intensive care unit over a decade. Crit Care Med 2010;38:59-64.

17. Becker S, Müller J, de Heer G, et al. Clinical characteristics and outcome of very elderly patients $>/=90$ years in intensive care: a retrospective observational study. Ann Intensive Care 2015;5:53.

18. Heyland DK, Garland A, Bagshaw SM, et al. Recovery after critical illness in patients aged 80 years or older: a multi-center prospective observational cohort study. Intensive Care Med 2015;41:1911-20.

19. Heyland DK, Stelfox HT, Garland A, et al. Predicting Performance Status 1 Year After Critical Illness in Patients 80 Years or Older: Development of a Multivariable Clinical Prediction Model. Crit Care Med 2016;44:1718-26.

20. Orsini J, Butala A, Salomon S, et al. Prognostic factors associated with adverse outcome among critically ill elderly patients admitted to the intensive care unit. Geriatr Gerontol Int 2015;15:889-94.

21. Mukhopadhyay A, Tai BC, See KC, et al. Risk factors for hospital and long-term mortality of critically ill elderly patients admitted to an intensive care unit. Biomed Res Int 2014;2014:960575.

22. Farfel JM, Franca SA, Sitta Mdo C, et al. Age, invasive ventilatory support and outcomes in elderly patients admitted to intensive care units. Age Ageing 2009;38:515-20.

23. Khouri T, Kabeshova A, Annweiler C, et al. Amount of care per survivor in young and older patients hospitalized in intensive care unit: a retrospective study. J Gerontol A Biol Sci Med Sci 2014;69:1291-8.

24. Needham DM, Bronskill SE, Calinawan JR, et al. Projected incidence of mechanical ventilation in Ontario to 2026: Preparing for the aging baby boomers. Crit Care Med 2005;33:574-9.

25. Schoenfeld DA, Bernard GR, ARDS Network. Statistical evaluation of ventilator-free days as an efficacy measure in clinical trials of treatments for acute respiratory distress syndrome. Crit Care Med 2002;30:1772-7.

26. Knaus WA, Draper EA, Wagner DP, et al. APACHE II: a severity of disease classification system. Crit Care Med 1985;13:818-29.

27. Esteban A, Anzueto A, Frutos-Vivar F, et al. Outcome of older patients receiving mechanical ventilation. Intensive Care Med 2004;30:639-46.

28. Esteban A, Anzueto A, Frutos F, et al. Characteristics and outcomes in adult patients receiving mechanical ventilation: a 28-day international study. JAMA 2002;287:345-55.

29. Lieberman D, Nachshon L, Miloslavsky O, et al. Elderly patients undergoing mechanical ventilation in and out of intensive care units: a comparative, prospective study of 579 ventilations. Crit Care 2010;14:R48. 
30. Añon JM, Gómez-Tello V, González-Higueras E, et al. Prognosis of elderly patients subjected to mechanical ventilation in the ICU. Med Intensiva 2013;37:149-55.

31. Torres OH, Francia E, Longobardi V, et al. Short- and long-term outcomes of older patients in intermediate care units. Intensive Care Med 2006;32:1052-9.

32. Su KC, Tsai CC, Chou KT, et al. Spontaneous breathing trial needs to be prolonged in critically ill and older patients requiring mechanical ventilation. J Crit Care 2012;27:324.e1-7.

33. Boumendil A, Somme D, Garrouste-Orgeas M, et al. Should elderly patients be admitted to the intensive care unit? Intensive Care Med 2007;33:1252.

34. Hennessy D, Juzwishin K, Yergens D, et al. Outcomes of elderly survivors of intensive care: a review of the literature. Chest 2005;127:1764-74.

35. Zhu Y, Yin H, Zhang R, et al. Gastric versus postpyloric enteral nutrition in elderly patients (age $>/=75$ years) on mechanical ventilation: a single-center randomized trial.

Cite this article as: $\mathrm{Ma} \mathrm{JG}$, Zhu B, Jiang L, Jiang Q, Xi XM. Clinical characteristics and outcomes of mechanically ventilated elderly patients in intensive care units: a Chinese multicentre retrospective study. J Thorac Dis 2021;13(4):2148-2159. doi: $10.21037 /$ jtd-20-2748
Crit Care 2018;22:170.

36. Pan CX, Platis D, Maw MM, et al. How Long Does (S)He Have? Retrospective Analysis of Outcomes After Palliative Extubation in Elderly, Chronically Critically Ill Patients. Crit Care Med 2016;44:1138-44.

37. Esteban A, Anzueto A, Alía I, et al. How is mechanical ventilation employed in the intensive care unit? An international utilization review. Am J Respir Crit Care Med 2000;161:1450-8.

38. Metnitz PG, Metnitz B, Moreno RP, et al. Epidemiology of mechanical ventilation: analysis of the SAPS 3 database. Intensive Care Med 2009;35:816-25.

39. Chelluri L, Mendelsohn AB, Belle SH, et al. Hospital costs in patients receiving prolonged mechanical ventilation: does age have an impact? Crit Care Med 2003;31:1746-51.

40. Turnbull AE, Lau BM, Ruhl AP, et al. Age and decisions to limit life support for patients with acute lung injury: a prospective cohort study. Crit Care 2014;18:R107. 